\title{
Effectiveness of internet-based interventions for children, youth, and young adults with anxiety and/or depression: a systematic review and meta-analysis
}

Xibiao Ye ${ }^{1,2^{*}}$, Sunita Bayyavarapu Bapuji ${ }^{1}$, Shannon Elizabeth Winters ${ }^{1,6,7}$, Ashley Struthers ${ }^{1}$, Melissa Raynard ${ }^{3}$, Colleen Metge ${ }^{1,2}$, Sara Adi Kreindler ${ }^{1,2}$, Catherine Joan Charette ${ }^{1}$, Jacqueline Angela Lemaire ${ }^{4}$,

Margaret Synyshyn ${ }^{5}$ and Karen Sutherland ${ }^{5}$

\begin{abstract}
Background: The majority of internet-based anxiety and depression intervention studies have targeted adults. An increasing number of studies of children, youth, and young adults have been conducted, but the evidence on effectiveness has not been synthesized. The objective of this research is to systematically review the most recent findings in this area and calculate overall (pooled) effect estimates of internet-based anxiety and/or depression interventions.
\end{abstract}

Methods: We searched five literature databases (PubMed, EMBASE, CINAHL, Psychlnfo, and Google Scholar) for studies published between January 1990 and December 2012. We included studies evaluating the effectiveness of internet-based interventions for children, youth, and young adults (age <25 years) with anxiety and/or depression and their parents. Two reviewers independently assessed the risk of bias regarding selection bias, allocation bias, confounding bias, blinding, data collection, and withdrawals/dropouts. We included studies rated as high or moderate quality according to the risk of bias assessment. We conducted meta-analyses using the random effects model. We calculated standardized mean difference and its 95\% confidence interval (95\% Cl) for anxiety and depression symptom severity scores by comparing internet-based intervention vs. waitlist control and internet-based intervention vs. face-to-face intervention. We also calculated pooled remission rate ratio and 95\% Cl.

Results: We included seven studies involving 569 participants aged between 7 and 25 years. Meta-analysis suggested that, compared to waitlist control, internet-based interventions were able to reduce anxiety symptom severity (standardized mean difference and $95 \% \mathrm{Cl}=-0.52[-0.90,-0.14]$ ) and increase remission rate (pooled remission rate ratio and $95 \% \mathrm{Cl}=3.63[1.59,8.27])$. The effect in reducing depression symptom severity was not statistically significant (standardized mean difference and $95 \% \mathrm{Cl}=-0.16[-0.44,0.12])$. We found no statistical difference in anxiety or depression symptoms between internet-based intervention and face-to-face intervention (or usual care).

(Continued on next page)

\footnotetext{
* Correspondence: xibiao.ye@gmail.com

${ }^{1}$ Centre for Healthcare Innovation Evaluation Platform, Winnipeg Regional Health Authority, 200-1155 Concordia Avenue, Winnipeg, Manitoba R2K 2M9, Canada

${ }^{2}$ Department of Community Health Sciences, Faculty of Medicine, University of Manitoba, Winnipeg, Manitoba, Canada

Full list of author information is available at the end of the article
} 
(Continued from previous page)

Conclusions: The present analysis indicated that internet-based interventions were effective in reducing anxiety symptoms and increasing remission rate, but not effective in reducing depression symptom severity. Due to the small number of higher quality studies, more attention to this area of research is encouraged.

Trial registration: PROSPERO registration: CRD42012002100

Keywords: Internet-based intervention, Anxiety, Depression, Child and youth, Effectiveness

\section{Background}

Up to $20 \%$ of children, youth, and young adults are affected by mental disorders each year [1,2], but less than $50 \%$ of those patients received specialized treatment services $[2,3]$. Modern information technologies offer new opportunities to deliver mental health interventions via computer-based or mobile phone based internet. The majority of internetbased mental health interventions have been aimed at adults [4], particularly those with anxiety and depression disorders [5-10]. These studies have shown that internetbased interventions were feasible and improved access and patient mental health outcomes in adults.

With the dramatically increased adoption of internetbased devices among the young population, studies have recently started to include children, youth, and young adults with anxiety and depression concerns [11-16]. Two recent narrative reviews have overviewed the findings of internet-based programs for anxiety and depression in children, youth, and young adults $[17,18]$, but neither of them calculated pooled effect estimates using metaanalysis methods. Internet-based mental health services may lower the overall cost by saving staff and client time and by minimizing the use of other resources such as clinic rooms $[19,20]$, but the empirical evidence has not been systematically examined. We sought to systematically review the most recent findings and calculate overall (pooled) effect estimates of internet-based anxiety and depression interventions in children, youth and young adults.

\section{Methods}

Detailed analysis protocol was registered with the International Prospective Register of Systematic Reviews (PROSPERO registration number: CRD42012002100).

\section{Inclusion and exclusion criteria}

We used the P.I.C.O.S. (Population, Interventions, Comparators, Outcomes, and Study Design) framework to identify relevant studies. Our focus was on children, youth, and young adults (age $<25$ years). Studies targeting parents of children (especially young children) with a mental health disorder/problem were also included. We excluded studies that did not clearly state study population characteristics. Interventions of interest were those targeting anxiety and/or depression symptoms and were delivered via the Internet (fixed or mobile internet). We considered both parallel comparisons (randomized or non-randomized controlled trials), pre-/post-intervention comparison studies, and observational studies. The primary outcomes of interest were anxiety and/or depression symptom severity and diagnosis (e.g., symptom scale scores and remission rates). We excluded studies solely evaluating participant expectations, experiences, and/or acceptance.

\section{Literature search}

A health science librarian (M.R.) conducted a literature search of multiple bibliographic databases including PubMed/Medline, EMBASE, CINAHL, PsychInfo/Proquest and Google Scholar (1990-2012) using both subject headings/terms and free text keywords. Heading and free text terms used to capture the concept of electronic provision of services included: e-mental, emental, ehealth, e-health, internet, virtual, mobile health, mhealth, m-health, mobile phone, cell phone, cellular phone, smartphone, iphone, tablet, ipad, information communication technology, text message, mobile message, message boards, social media, facebook, twitter, myspace, google+, blogging, and telemedicine. These terms were then combined with subject and free text terms describing mental health services (e.g., delivery of health care, health services accessibility, delivery of mental health services, mental health services, community mental health services, etc.) and terms describing youth, children and adolescents to capture the literature containing information about the electronic provision of mental health services to this age group. This search strategy was designed for PubMed/Medline, then translated for use in the other databases. A Google search using the search terms mentioned above was also undertaken to locate grey literature. We limited our search to articles published since 1990.

Titles and abstracts of articles were scanned by two reviewers (S.B.B. and S.E.W.) independently to make an initial assessment of relevance based on the inclusion and exclusion criteria. The two reviewers met regularly to reach a consensus on relevance of each title and abstract. When the information was not enough to judge the relevance, the full-text was retrieved. Articles that did not provide sufficient information on the P.I.C.O.S. framework elements or did not meet the inclusion criteria as defined using the framework were considered irrelevant and were thus excluded. Reviewers also hand- 
searched references cited in those articles to maximize the number of studies identified.

\section{Study appraisal and selection}

Two reviewers (S.B.B. and S.E.W.) independently evaluated the quality of screened studies using a modified version of the Quality Assessment Tool for Quantitative Studies [21] and rated each of the six quality components: selection bias (bias caused by systematic differences between those who are selected for a study and those who are not), allocation bias (bias caused by non-random allocation of participants to intervention and control groups), confounding bias (bias due to the presence of a common cause of exposure/intervention and outcome), blinding (researchers and/or participants are unaware of the group to which the participants are assigned to), data collection methods (validity and reliability of data collection tools), and withdrawals/dropouts (the percentage of participants that do not complete the study or dropped out). Reviewers independently rated each component as strong, moderate, or weak and assigned a global quality rating to each study: strong quality (four strong ratings with no weak ratings); moderate quality (less than four strong ratings and one weak rating); weak quality (two or more weak ratings). Reviewers met regularly to reach a consensus and disagreements were discussed and resolved in team meetings with senior investigators (X.Y. and C.M.). We developed a data extraction form and pilot-tested it on five articles. A reviewer extracted information on study characteristics (e.g., design, location), participant characteristics (e.g., age, sex, enrollment approach), intervention (e.g., number of intervention groups, comparison, intervention details), and results. A second reviewer checked the extracted data and any disagreements were solved between the two reviewers or by involving a third author when necessary.

\section{Data analysis}

We included high or moderate quality studies in the metaanalysis. We used the random effects meta-analysis model to estimate pooled intervention effects. Effect estimates based on intent-to-treat analysis were used whenever applicable; otherwise complete-sample-analysis results were used. We examined heterogeneity among studies using Cochran's Q test and Higgins' $\mathrm{I}^{2}$ statistics according to the Cochrane Handbook [22]. $\mathrm{I}^{2}<30 \%$ and $\mathrm{I}^{2}=30-50 \%$ were considered the presence of minimal heterogeneity and moderate heterogeneity, respectively [22]. For continuous outcomes (i.e., anxiety/depression symptom scores), we calculated standardized mean differences and its 95\% confidence intervals (95\% CIs) between an internet-based intervention and control and between an internet-based intervention and face-to-face intervention (or usual care) [22]. For the binary outcome (i.e., remission rate), we calculated a pooled rate ratio and $95 \%$ CI. To test the robustness of the pooled effect estimates, we reran the models by using anxiety/depression outcomes measured by alternative instruments (each study assessed anxiety/ depression symptoms using multiple instruments simultaneously). We also reran the model after excluding studies that were not CBT based. We undertook a subgroup analysis by methodology quality rating (strong vs. moderate). Significant level was set at 0.05 . We rated the quality of the synthesized evidence using the GRADE approach [23]. All analyses were undertaken in RevMan 5.2.

\section{Results}

Figure 1 describes the process and the number of studies reviewed at each step. We included three strong and four moderate quality studies, all randomized controlled trials (RCTs), in this analysis after excluding eight weak quality studies and one partially duplicate study (see Additional file 1: Table S1). Of the seven studies, six were published in peer-reviewed journals, and one was a doctoral dissertation [11]. These studies enrolled a total of 569 participants aged between 7 and 25 years (Table 1). Participants were diagnosed with anxiety disorders in four studies, with anxiety and/or depression in one study, and did not have a specified diagnosis in two studies (but focusing on reducing participants' anxiety and depression symptoms). All studies but one [13] explicitly stated that cognitive behavioral therapy (CBT) was applied in the interventions. Intervention group participants in this study used a mobile phone based tool to self-monitor their mood, stress, and alcohol and cannabis use daily and received short text message (SMS) and phone call supports from psychologists [13]. Interventions in all studies included online selfhelp sessions; six studies supplemented online self-help with therapist support via email, SMS, and/or phone call (one of the six studies also included family support [16]); and one study included school-based group support and teacher support [12]. Participants accessed to the online intervention contents at home or school (the same settings where they normally access the internet). The duration of interventions ranged from 3 to 12 weeks. All included studies compared an internet-based intervention to a waitlist control group and two also compared an internet-based intervention to a face-to-face intervention (or usual care). Six studies measured both anxiety and depression symptoms as primary outcomes and the remaining one focused on depression symptoms only [12]. All studies used more than one outcome instrument, but no single instrument was used in all of the studies. Outcomes were measured pre- and post-intervention at different time points (up to 12 months).

We first compared internet-based interventions to waitlist control. Meta-analysis suggested that internet-based interventions were able to reduce anxiety symptom severity compared to waitlist control (standardized mean 


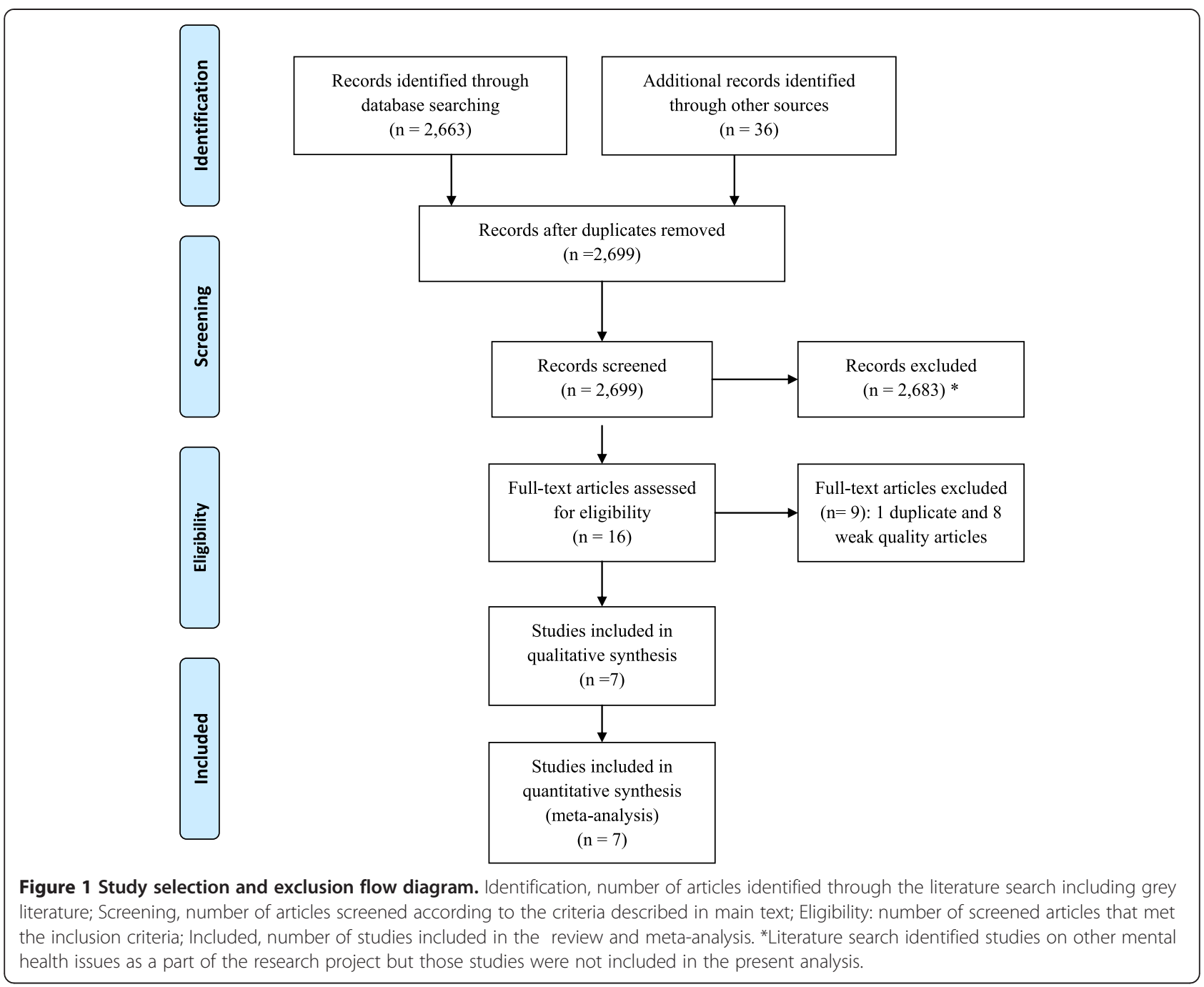

difference and $95 \% \mathrm{CI}=-0.52[-0.90,-0.14]$, $\mathrm{p}$ for heterogeneity test $=0.02, \mathrm{I}^{2}=62 \%$ ), as shown in Figure 2(a). Sensitivity analysis, by removing the study that was not described as CBT-based, did not change the overall effect estimate. Participants receiving internet-based interventions were also more likely than waitlist controls to be free of a diagnosis of anxiety disorder after the treatment (remission rate ratio and $95 \% \mathrm{CI}=3.63[1.59$, 8.27], $\mathrm{p}$ for heterogeneity test $=0.87, \mathrm{I}^{2}=0 \%$ ), Figure $2(\mathrm{~b}$ ). However, the effect in reducing depression symptom severity was not statistically significant (standardized mean difference and $95 \% \mathrm{CI}=-0.16[-0.44,0.12]$, $\mathrm{p}$ for heterogeneity test $=0.05, \mathrm{I}^{2}=53 \%$ ), Figure $2(\mathrm{c})$. Subgroup analysis has shown similar results between studies with different quality ratings (strong vs. moderate).

The meta-analysis of the two studies comparing internetbased intervention to face-to-face intervention showed no statistical differences in intervention effects of anxiety symptoms (standardized mean difference and 95\% $\mathrm{CI}=-0.08[-0.50,0.35], \mathrm{p}$ for heterogeneity test $=0.57, \mathrm{I}^{2}=$
$0 \%)$ or depression symptoms (standardized mean difference and $95 \% \mathrm{CI}=1.32[-0.26,2.90]$, $\mathrm{p}$ for heterogeneity test $\left.=0.02, \mathrm{I}^{2}=82 \%\right)$, as shown in Figures $3(\mathrm{a})$ and (b).

The majority of studies examined short term effects (effects at the end of the intervention or less than 12 weeks post intervention). Two studies followed the intervention group participants but not the control group participants 6 months and 12 months after the interventions, respectively, and found the improvement (compared to pre-intervention) retained [14,24]. However, only one study followed participants in both the intervention and control groups for 12 months after the intervention [14] and showed no intervention effect at this time point. In one study [11], participants had a lower anxiety level 6 weeks after the intervention, but this effect disappeared 12 weeks after the intervention.

\section{Discussion}

Our analyses demonstrated that internet-based interventions were effective in reducing anxiety symptom severity 
Table 1 Characteristics of Studies of Internet-based anxiety and depression interventions among children, youth, and young adults

\begin{tabular}{|c|c|c|c|c|c|c|c|}
\hline \multirow[t]{2}{*}{ Reference } & \multirow[t]{2}{*}{ Study design } & \multirow[t]{2}{*}{ Participant } & \multirow{2}{*}{$\begin{array}{l}\text { No. of } \\
\text { participants }\end{array}$} & \multicolumn{2}{|l|}{ Intervention } & \multicolumn{2}{|l|}{ Outcome } \\
\hline & & & & Intervention contents & $\begin{array}{l}\text { Intervention } \\
\text { duration }\end{array}$ & Primary outcomes & Time of measurement \\
\hline $\begin{array}{l}\text { Keller, } \\
2010[11]\end{array}$ & $\begin{array}{l}\text { 2-arm RCT (Internet } \\
\text { program vs. Waitlist } \\
\text { control) }\end{array}$ & $\begin{array}{l}\text { Children with anxiety and } \\
\text { mothers }\end{array}$ & 37 & $\begin{array}{l}\text { Computer-based CBT program } \\
\text { (self-help + therapist support) }\end{array}$ & 12 weeks & $\begin{array}{l}\text { Anxiety, depression, and social } \\
\text { phobia symptom assessment } \\
\text { scores }\end{array}$ & $\begin{array}{l}\text { Baseline, } 6 \text { and } 12 \text { weeks } \\
\text { after the intervention }\end{array}$ \\
\hline $\begin{array}{l}\text { March, } \\
2009[24]\end{array}$ & $\begin{array}{l}\text { 2-arm RCT (Internet-based } \\
\text { CBT vs. Waitlist control) }\end{array}$ & $\begin{array}{l}\text { Children ( } 7-12 \text { years) with } \\
\text { anxiety disorders and } \\
\text { parents }\end{array}$ & 73 & $\begin{array}{l}\text { Computer -based CBT program } \\
\text { (self-help sessions + therapist } \\
\text { support through email and } \\
\text { phone) }\end{array}$ & $\begin{array}{l}10 \text { weeks for } \\
\text { children and } \\
6 \text { weeks for } \\
\text { parents } \\
\text { (60 minutes per } \\
\text { session) }\end{array}$ & $\begin{array}{l}\text { Anxiety diagnostic status and } \\
\text { severity, number of anxiety } \\
\text { diagnoses, anxiety and } \\
\text { depression symptom } \\
\text { assessment scores }\end{array}$ & $\begin{array}{l}\text { Baseline, the end of } \\
\text { intervention, and } \\
6 \text { months after the } \\
\text { intervention (for } \\
\text { intervention group only) }\end{array}$ \\
\hline $\begin{array}{l}\text { Storch, } \\
2011[16]\end{array}$ & $\begin{array}{l}\text { 2-arm RCT (Internet-based } \\
\text { CBT vs. Waitlist control) }\end{array}$ & $\begin{array}{l}\text { Children and adolescents } \\
\text { ( } 7-16 \text { years) with } \\
\text { obsessive compulsive } \\
\text { disorder and at least one } \\
\text { parent }\end{array}$ & 31 & $\begin{array}{l}\text { Family based CBT treatment } \\
\text { delivered via computer-based } \\
\text { internet (self-help sessions + } \\
\text { online therapist support) }\end{array}$ & 12 weeks & $\begin{array}{l}\text { Anxiety and depression } \\
\text { symptom assessment scores, } \\
\text { remission rate post intervention }\end{array}$ & $\begin{array}{l}\text { Baseline and the end of } \\
\text { intervention }\end{array}$ \\
\hline $\begin{array}{l}\text { Spence, } \\
2011[14]\end{array}$ & $\begin{array}{l}\text { 3-arm RCT (Internet-based } \\
\text { CBT vs. Clinic-based CBT } \\
\text { vs. Waitlist control) }\end{array}$ & $\begin{array}{l}\text { Adolescents ( } 12-18 \text { years) } \\
\text { with anxiety disorders } \\
\text { and parents }\end{array}$ & 115 & $\begin{array}{l}\text { Computer -based CBT treatment } \\
\text { (self-help session + online } \\
\text { therapist support through } \\
\text { email) or clinic-based CBT } \\
\text { treatment }\end{array}$ & 10 weeks & $\begin{array}{l}\text { Anxiety diagnostic status, } \\
\text { anxiety and depression } \\
\text { symptom severity }\end{array}$ & $\begin{array}{l}\text { Baseline, } 3,6 \text {, and } \\
12 \text { months after the } \\
\text { intervention }\end{array}$ \\
\hline $\begin{array}{l}\text { O'Kearney, } \\
2009[12]\end{array}$ & $\begin{array}{l}\text { 2-arm RCT (Internet-based } \\
\text { curriculum vs. Waitlist } \\
\text { control) }\end{array}$ & $\begin{array}{l}\text { Adolescent girls (15-16 } \\
\text { years) }\end{array}$ & 157 & $\begin{array}{l}\text { Computer -based CBT program } \\
\text { MoodGYM (self-help + school- } \\
\text { based group support + teacher } \\
\text { support) }\end{array}$ & $\begin{array}{l}6 \text { weeks (for } 3 \\
\text { modules) }\end{array}$ & $\begin{array}{l}\text { Depression diagnosis and } \\
\text { symptom assessment scores, } \\
\text { attributional style }\end{array}$ & $\begin{array}{l}\text { Baseline, the end of } \\
\text { intervention, and } \\
20 \text { weeks after the } \\
\text { intervention }\end{array}$ \\
\hline $\begin{array}{l}\text { Sethi, } \\
2010[15]\end{array}$ & $\begin{array}{l}\text { 4-arm RCT (Internet-based } \\
\text { CBT vs. Face-to-face CBT } \\
\text { vs. Combined face-to-face/ } \\
\text { online CBT vs. Control) }\end{array}$ & $\begin{array}{l}\text { Students (15-25 years) } \\
\text { with low or moderate } \\
\text { level of anxiety/ } \\
\text { depression }\end{array}$ & 38 & $\begin{array}{l}\text { Computer -based CBT program } \\
\text { MoodGYM delivered at school } \\
\text { or at home (self-help sessions + } \\
\text { therapist support) }\end{array}$ & $\begin{array}{l}5 \text { sessions within } \\
3 \text { weeks }\end{array}$ & $\begin{array}{l}\text { Depression, anxiety, and distress } \\
\text { symptoms }\end{array}$ & $\begin{array}{l}\text { Baseline and the end of } \\
\text { intervention }\end{array}$ \\
\hline $\begin{array}{l}\text { Reid, } \\
2011 \text { [13] }\end{array}$ & $\begin{array}{l}\text { 2-arm RCT (Mobile phone- } \\
\text { based intervention vs. } \\
\text { Control) }\end{array}$ & $\begin{array}{l}\text { Youth with mild or more } \\
\text { severe emotional/mental } \\
\text { health issue but no severe } \\
\text { psychiatric condition }\end{array}$ & 118 & $\begin{array}{l}\text { Mobile phone-based self- } \\
\text { monitoring }+ \text { SMS and phone } \\
\text { call support by psychologist }\end{array}$ & 6 weeks & $\begin{array}{l}\text { Depression, anxiety, and distress } \\
\text { symptoms }\end{array}$ & $\begin{array}{l}\text { Baseline, the end of } \\
\text { intervention, and } 6 \text { weeks } \\
\text { after the intervention }\end{array}$ \\
\hline
\end{tabular}

CBT, cognitive behavioral therapy; RCT, randomized controlled trial; SMS, short text message. 
(a) Anxiety symptom severity score

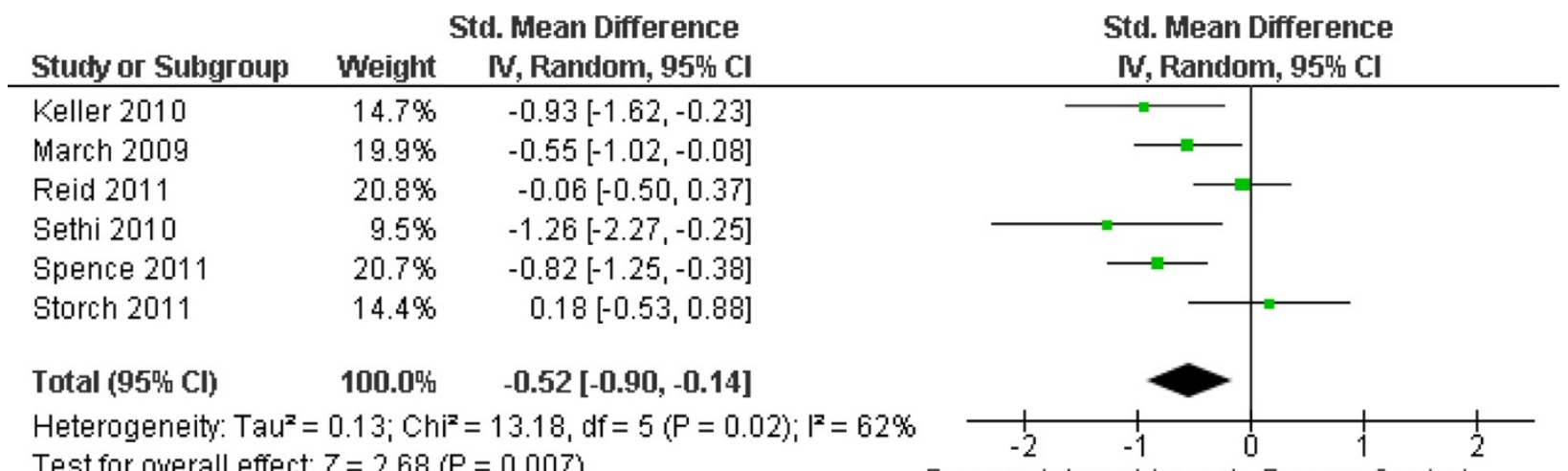

Test for overall effect: $Z=2.68(P=0.007)$

Favours Internet-based Favourscontrol

(b) Anxiety remission rate

Study or Subgroup Weight $\mathrm{H}-\mathrm{H}$, Random, 95\% $\mathrm{Cl}$

Risk Ratio

$\begin{array}{lrr}\text { March 2009 } & 46.8 \% & 2.90[0.87,9.66] \\ \text { Spence 2011 } & 16.6 \% & 4.91[0.65,37.11] \\ \text { Storch 2011 } & 36.6 \% & 4.22[1.08,16.45]\end{array}$

W-H, Random, 95\% Cl

Total $(95 \%$ 嗢 $\mathrm{Cl}) \quad 100.0 \% \quad 3.63[1.59,8.27]$

Total events

Heterogeneity: $\operatorname{Tau}^{2}=0.00 ; \mathrm{Ch}^{2}=0.27, \mathrm{df}=2(\mathrm{P}=0.87) ; \mathrm{I}^{2}=0 \%$

Test for overall effect: $Z=3.07(\mathrm{P}=0.002)$

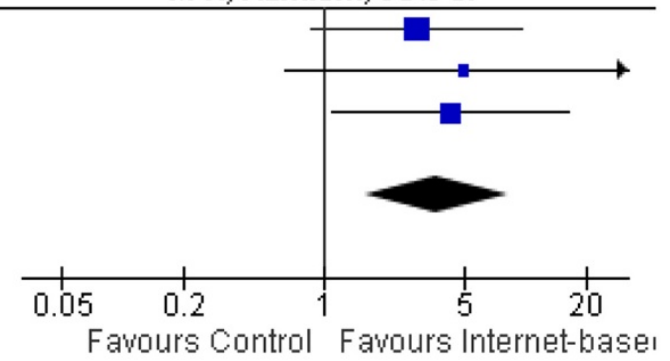

(c) Depression symptom severity score

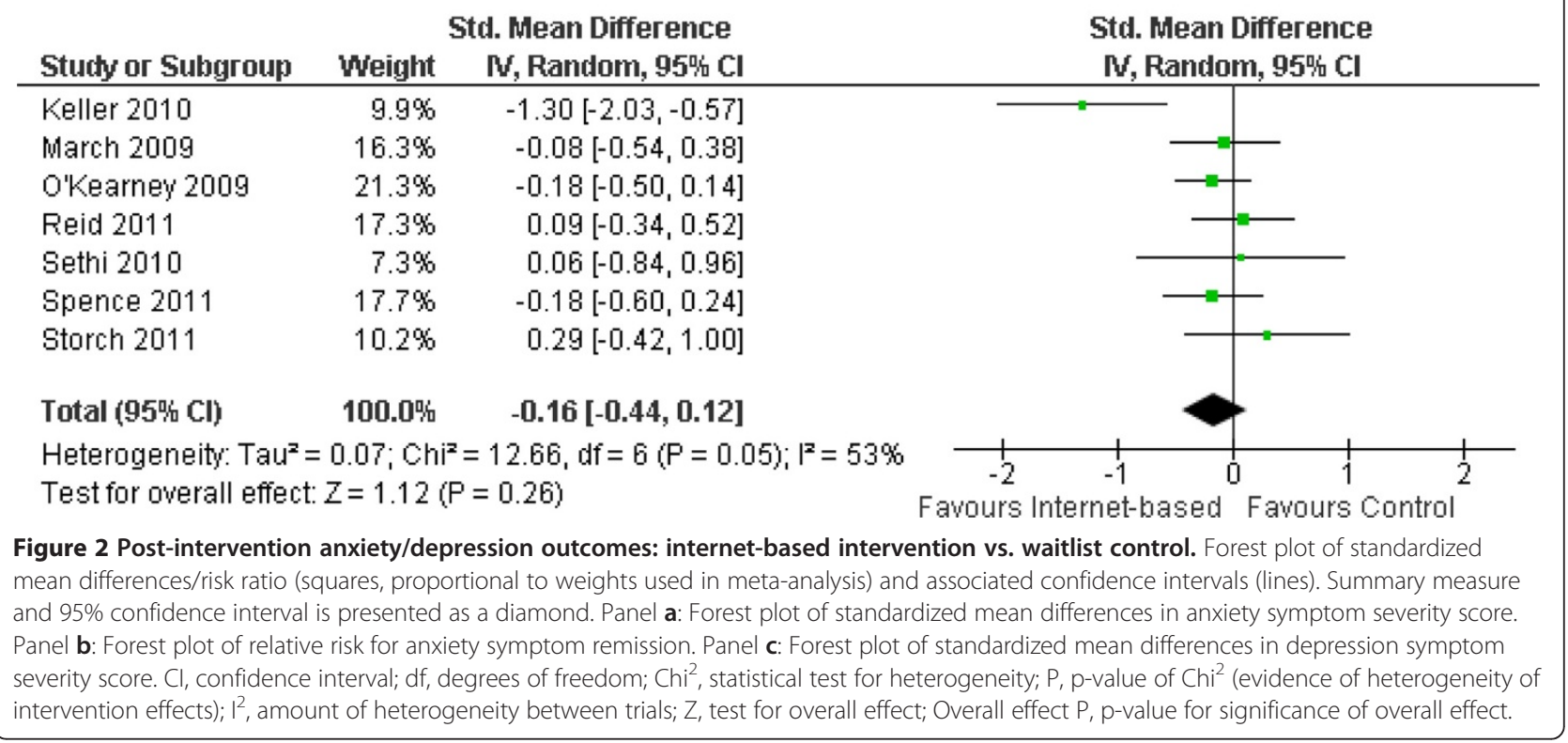

compared to no intervention, and this effect may be equal to that of face-to-face interventions (or usual care). The findings support the observations in the two previous narrative reviews where the majority of studies showed positive effects $[17,18]$. This is also consistent with the findings from meta-analyses of internet-based interventions in 
(a) Anxiety symptom severity score

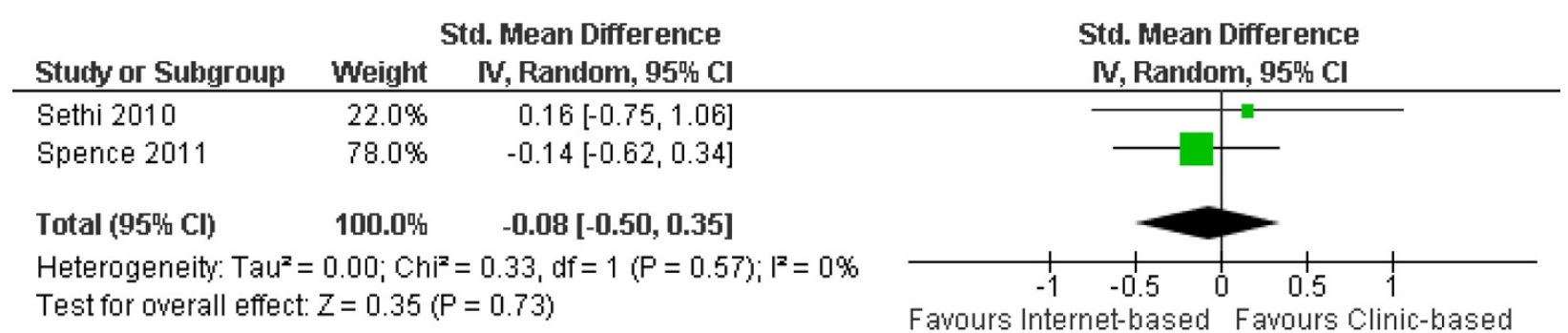

(b) Depression symptom severity score *

\begin{tabular}{|c|c|c|c|}
\hline Stucty or Subgroup & Weight & $\begin{array}{l}\text { td. Mean Difference } \\
\text { N, Random, 95\% Cl }\end{array}$ & $\begin{array}{l}\text { Std. Mean Difference } \\
\text { W, Random, 95\% Cl }\end{array}$ \\
\hline Sethi 2010 & $44.6 \%$ & $2.22[1.02,3.42]$ & \begin{tabular}{l|l}
$-\longrightarrow$ \\
\end{tabular} \\
\hline Spence 2006 & $55.4 \%$ & $0.60[0.01,1.19]$ & \\
\hline Total (95吹 Cl) & $100.0 \%$ & $1.32[-0.26,2.90]$ & \\
\hline \multicolumn{3}{|c|}{$\begin{array}{l}\text { Heterogeneity: } \operatorname{Tau}^{2}=1.08 ; \mathrm{Chi}^{2}=5.63, \mathrm{df}=1(\mathrm{P}=0.02) ; \mathrm{I}^{2}=82 \% \\
\text { Test for overall effect: } Z=1.64(\mathrm{P}=0.10)\end{array}$} & 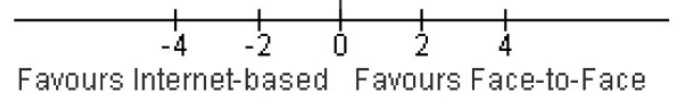 \\
\hline \multicolumn{4}{|c|}{$\begin{array}{l}\text { Figure } 3 \text { Post-intervention anxiety/depression symptom scores: internet-based intervention vs. face-to-face intervention. Forest plot of } \\
\text { standardized mean differences (squares, proportional to weights used in meta-analysis) and associated confidence intervals (lines). Summary } \\
\text { measure and 95\% confidence interval is presented as a diamond. Panel a: Forest plot of standardized mean differences in anxiety symptom } \\
\text { severity score. Panel b: Forest plot standardized mean differences in depression symptom severity score. (*Depression data were reported in (S. H. } \\
\text { Spence, Holmes, March, \& Lipp, 2006), an earlier analysis of the study (S. H. Spence et al., 2011)). }\end{array}$} \\
\hline
\end{tabular}

adults $[9,25,26]$. However, the quality of the evidence was low to moderate (see Additional file 1: Table S2). The limited extant findings suggest that augmentation of the internet interventions are required to maintain the positive effects.

The analysis, however, did not support the effect of internet-based interventions on reducing depression symptoms. The difference in the effects on the two disorders is consistent with findings from one previous systematic review of internet-based interventions for adult depression and anxiety [25]. The meta-analysis found a larger effect size for anxiety than for depression, which the authors believed was explained by the magnitude of therapist involvement but not the type of disorder. Therapist involvement might also explain the difference found in the present analysis since the study focusing on depression only was the only one without therapist support (although school and family supports were provided) [12]. Furthermore, more than half of the interventions in the present analysis were developed to primarily target anxiety disorders. Despite the high prevalence of comorbidity in the young population, depression and anxiety disorders are two different disorders with their own behavioral symptoms [27]. CBT interventions for the two disorders often contain similar contents [28]. Transdiagnostic CBT, an approach bringing therapeutic elements from disorder-specific CBTs together to treat diagnostically mixed patients, may offer several advantages but there is no sufficient evidence supporting the effectiveness of this approach versus control [29]. Few studies have found that internetbased transdiagnostic CBT improved patient outcomes when compared to control [30]. However, it is unclear whether transdiagnostic CBT performs better than disorder-specific CBTs [31]. Previous studies have indicated that even if a CBT intervention was effective in reducing anxiety or depression symptoms, the intervention might not work for the other comorbid condition [28]. Therefore, more research is needed to compare internet-based transdiagnostic CBT vs. disorder-specific CBT for anxiety and depression.

The interpretation of the findings from the current analysis needs to consider several factors. First, the combined effect estimates do not take into account baseline differences between comparative groups. Some of the included studies have found statistical differences in demographic characteristics and/or baseline anxiety/depression symptom scores between the participants in the intervention group and those in the control group $[12,14,16]$. Methods including change-from-baseline comparison, covariance 
analysis, and regression models can be used to adjust for baseline differences, but there were not enough data from the included studies to conduct a meta-analysis. Second, studies included in this analysis involved patients with mild or moderate anxiety/depression symptoms [13-16]. While the analysis indicates that internet-based intervention can improve symptoms in those patients, the interventions may not affect patients with severer symptoms. Third, intervention duration and outcome follow-up length varied across studies. We were not able to examine the long-term effect (greater than 12 weeks after the intervention), but individual studies have indicated that the intervention effect might not last over a long period of time $[11,14]$. Future studies should follow participants from both intervention and control groups for a longer time period in order to examine effect maintenance.

Many RCTs (particularly mobile device-based studies) initiated recently are still recruiting participants [32-34], therefore, were not included in the current analysis. The adoption of mobile devices (e.g., cell phone, smartphone, and tablet) has been dramatically increasing among the young population. Almost $80 \%$ of teens in America have a cell phone and almost half of them own smartphones [35]. Around a quarter of them also have a tablet computer [35]. Mobile devices offer greater mobility and provide new opportunities to enhance the delivery of mental health and other medical services [36,37]. With only one mobile phone-based study in the present analysis, we were not able to compare the effects of fixed internet-based interventions versus mobile-based interventions. A recent systematic review [38] found mobile phone based diabetes self-management had a larger effect than computer-based intervention. There was, however, no difference in effect size between mobile phone-based and computer-based adult depression interventions [39]. Given the rapid growth of mobile phone users (in particular smartphone users) and the advantages of mobile technologies, more studies are needed to examine the effectiveness of mobile phone-based intervention.

None of the included studies in this analysis evaluated the cost or the cost-effectiveness of internet-based interventions for children. Adult studies suggest computerized or internet-based CBTs for anxiety and depression are cost-effective [7,40,41]. These findings may not apply to children and youth because interventions for these patients usually require parent and school teacher involvement. Future studies should collect comprehensive cost data and long-term effect data in order to conduct economic analysis.

There are methodological limitations in the present meta-analysis. We included studies published in English only. This analysis was based on a small number of studies with inconsistent approaches for data analysis (i.e., complete-sample-analysis vs. intent-to-treat analysis).
Each study used several different instruments to assess anxiety and/or depression symptoms but only those measurements from instruments that were used more commonly across the studies (e.g., Beck Anxiety Inventory and Children's Depression Inventory) were included in the meta-analyses. However, replacing the outcomes with those from less commonly used instruments did not significantly change the combined effect estimates.

\section{Conclusions}

In conclusion, the analysis indicated that internet-based interventions were effective in reducing anxiety symptoms, and might be as effective as face-to-face interventions. However, the interventions may not work for depression. Stronger evidence is needed and future studies should also examine whether or not the interventions are cost-effective. Given the rapid adoption of mobile devices among children, youth, and young adults, it is also important to develop and evaluate mobile device based interventions.

\section{Additional file}

\section{Additional file 1: Table S1. Quality assessment of included studies.}

Table S2. Summary of Findings and Quality of Evidence.

\section{Abbreviations}

CBT: Cognitive behavioral therapy; P.I.C.O.S.: Population, intervention, comparator, outcome, and study design; $95 \% \mathrm{Cl}$ : 95\% confidence interval; RCTs: Randomized controlled trials.

\section{Competing interests}

No disclosed financial or nonfinancial competing interests by all authors.

\section{Authors' contributions}

$X Y$ conceived of the study, and led the design and execution of the synthesis and drafted the manuscript. CM and MS, a nominated principal applicant and a principal knowledge user, participated in designing the study and supervised the conduction of the study. SB and SW independently screened and assessed the quality of studies. MR conducted systematic literature search. AS, JL, CC, SK, and KS participated in quality assessment, data analysis and interpretation. All authors read and approved the final manuscript.

\section{Acknowledgements}

This work was funded by the Canadian Institute of Health Research (Grant No. KA1-119794). The funder had no role in study design, data collection, analysis, and interpretation. The authors acknowledge the support of Mrs. Judy Dyrland, Mr. Noah Star, and Dr. Olga Norrie.

Funding

Canadian Institutes of Health Research (Grant No. KA1-119794).

\section{Author details}

${ }^{1}$ Centre for Healthcare Innovation Evaluation Platform, Winnipeg Regional Health Authority, 200-1155 Concordia Avenue, Winnipeg, Manitoba R2K 2M9, Canada. ${ }^{2}$ Department of Community Health Sciences, Faculty of Medicine, University of Manitoba, Winnipeg, Manitoba, Canada. ${ }^{3}$ Concordia Hospital Library, University of Manitoba, 1095 Concordia Avenue, Winnipeg, Manitoba R2N 3S8, Canada. ${ }^{4}$ Addictions Foundation of Manitoba, 1031 Portage Avenue, Winnipeg, Manitoba R3G 0R8, Canada. ${ }^{5}$ Manitoba Adolescent Treatment Centre, 120 Tecumseh St, Winnipeg, Manitoba R3E 2A9, Canada. ${ }^{6}$ Health and Rehabilitation Sciences, Faculty of Health Sciences, Western University, London, ON N6G 1H1, Canada. ${ }^{7}$ Mental Health Crisis Response 
Centre, Winnipeg Regional Health Authority, 817 Bannatyne Avenue, Winnipeg MB R3E OW4, Canada.

Received: 18 December 2013 Accepted: 10 July 2014

Published: 18 July 2014

\section{References}

1. Belfer ML: A global perspective on child and adolescent mental health. Editorial. Int Rev Psychiatry 2008, 20(3):215-216.

2. Waddell C, McEwan K, Shepherd CA, Offord DR, Hua JM: A public health strategy to improve the mental health of Canadian children. Can J Psychiatry 2005, 50(4):226-233.

3. Merikangas KR, He JP, Brody D, Fisher PW, Bourdon K, Koretz DS: Prevalence and treatment of mental disorders among US children in the 2001-2004 NHANES. Pediatrics 2010, 125(75):75.

4. Christense $H$, Petrie $K$ : State of the e-mental health field in Australia: where are we now? Aust N Z J Obstet Gynaecol 2013, 47(2):117-120.

5. Griffiths KM, Farrer $L$, Christensen $H$ : The effectiveness of internet interventions for depression and anxiety disorders: a review of randomised controlled trials. Med J Aust 2010, 192(11 Suppl):S4-S11.

6. Ipser JC, Dewing S, Stein DJ: A systematic review of the quality of information on the treatment of anxiety disorders on the internet. Curr Psychiatry Rep 2007, 9(4):303-309.

7. McCrone P, Knapp M, Proudfoot J, Ryden C, Cavanagh K, Shapiro DA, Ilson S, Gray JA, Goldberg D, Mann A, Marks I, Everitt B, Tylee A: Cost-effectiveness of computerised cognitive-behavioural therapy for anxiety and depression in primary care: randomised controlled trial. Br J Psychiatry 2004, 185:55-62.

8. Reynolds J, Griffiths K, Christensen H: Anxiety and depression: online resources and management tools. Aust Fam Physician 2011, 40(6):382-386.

9. Reger MA, Gahm GA: A meta-analysis of the effects of Internet-and computer-based cognitive-behavioral treatments for anxiety. J Clin Psychol 2009, 65(1):53-75.

10. Van't Hof E, Cuijpers P, Stein DJ: Self-help and Internet-guided interventions in depression and anxiety disorders: a systematic review of meta-analyses. CNS Spectr 2009, 14(2 Suppl 3):34-40.

11. Keller ML: An internet cognitive-behavioral skills-based program for child anxiety. Diss Abstr Int 2010, 71(2-B):1344.

12. O'Kearney R, Kang K, Christensen H, Griffiths K: A controlled trial of a school-based internet program for reducing depressive symptoms in adolescent girls. Depress Anxiety 2009, 26(1):65-72.

13. Reid SC, Kauer SD, Hearps SJC, Crooke AHD, Khor AS, Sanci LA, Patton GC: A mobile phone application for the assessment and management of youth mental health problems in primary care: a randomised controlled trial. BMC Fam Pract 2011, 12:131.

14. Spence SH, Donovan CL, March S, Gamble A, Anderson RE, Prosser S, Kenardy J: A randomized controlled trial of online versus clinic-based CBT for adolescent anxiety. J Consult Clin Psychol 2011, 79(5):629-642.

15. Sethi $S$, Campbell AJ, Ellis LA: The use of computerized self-help packages to treat adolescent depression and anxiety. J Technol Hum Serv 2010, 28(3):144-160.

16. Storch EA, Caporino NE, Morgan JR, Lewin AB, Rojas A, Brauer L, Larson MJ, Murphy TK: Preliminary investigation of web-camera delivered cognitive-behavioral therapy for youth with obsessive-compulsive disorder. Psychiatry Res 2011, 189(3):407-412.

17. Calear AL, Christensen H: Review of internet-based prevention and treatment programs for anxiety and depression in children and adolescents. Med J Aust 2010, 192(11 Suppl):S12-S14.

18. Richardson T, Stallard P, Velleman S: Computerised cognitive behavioural therapy for the prevention and treatment of depression and anxiety in children and adolescents: a systematic review. Clin Child Fam Psychol Rev 2010, 13(3):275-290.

19. Christensen $\mathrm{H}$, Hickie IB: E-mental health: a new era in delivery of mental health services. Med J Aust 2010, 192(11 Suppl):S2-S3.

20. Christensen $\mathrm{H}$, Hickie IB: Using e-health applications to deliver new mental health services. Med J Aust 2010, 192(11 Suppl):S53-S56.

21. Thomas BH, Ciliska D, Dobins M, Micucci S: A process for systematically reviewing the literature: providing the research evidence for public health nursing interventions. Worldviews Evid Based Nurs 2004, 1(3):176-184.

22. Higgins JPT, Green S: Cochrane Handbook for Systematic Reviews of Interventions. West Sussex, England: John and Wiley \& Sons Ltd; 2011.
23. Guyatt GH, Oxman AD, Vist GE, Kunz R, Falck-Ytter Y, Alonso-Coello P, Schunemann HJ: GRADE: an emerging consensus on rating quality of evidence and strength of recommendations. BMJ 2008, 336:924-926.

24. March S, Spence SH, Donovan CL: The effectiveness of an internet-based cognitive-behavioral therapy intervention for child anxiety disorders. J Pediatr Psychol 2009, 34(5):474-487.

25. Spek V, Cuijpers P, Nyklicek I, Riper H, Keyzer J, Pop V: Internet-based cognitive behavior therapy for symptoms of depression and anxiety: a meta-analysis. Psychol Med 2007, 37:319-328.

26. Andrews G, Cuijpers P, Craske MG, McEvoy P, Titov N: Computer therapy for the anxiety and depressive disorders is effective, acceptable and practical health care: a meta-analysis. PLoS One 2010, 5(10):e13196.

27. Cerda M, Sagdeo A, Galea S: Comorbid forms of psychopathology: key patterns and future research directions. Epidemiol Rev 2008, 30:155-177.

28. Garber J, Weersing VR: Comorbidity of anxiety and depression in youth: implications for treatment and prevention. Clin Psychol (New York) 2010, 17(4):293-306.

29. Clark DA: Cognitive behavioral therapy for anxiety and depression: possibilities and limitations of a transdiagnostic perspective. Cogn Behav Ther 2009, 38(SUPPL.1):29-34

30. Mewton L, Smith J, Rossouw P, Andrews G: Current perspectives on internet-delivered cognitive behavioral therapy for adults with anxiety and related disorders. Psychol Res Behav Manag 2014, 7:37-46.

31. Craske MG: Transdiagnostic treatment for anxiety and depression. Depress Anxiety 2012, 29(9):749-753.

32. Whittaker R, Merry S, Dorey E, Maddison R: A development and evaluation process for mhealth interventions: examples from New Zealand. J Health Commun 2012, 17(SUPPL. 1):11-21.

33. Van Den Berg N, Grabe H, Freyberger HJ, Hoffmann W: A telephone- and text-message based telemedical care concept for patients with mental health disorders - Study protocol for a randomized, controlled study design. BMC Psychiatry 2011, 11:30.

34. Ekberg J, Timpka T, Bång M, Fröberg A, Halje K, Eriksson H: Cell phonesupported cognitive behavioural therapy for anxiety disorders: a protocol for effectiveness studies in frontline settings. BMC Med Res Methodol 2011, 11:3.

35. Teens and technology. 2013, http://www.pewinternet.org/Reports/2013/ Teens-and-Tech.aspx.

36. Ehrenreich B, Righter B, Rocke DA, Dixon L, Himelhoch S: Are mobile phones and handheld computers being used to enhance delivery of psychiatric treatment? A systematic review. J Nerv Ment Dis 2011, 199(11):886-891.

37. Luxton DD, McCann RA, Bush NE, Mishkind MC, Reger GM: MHealth for mental health: integrating Smartphone technology in behavioral healthcare. Prof Psychol: Res Prac 2011, 42(6):505-512.

38. Pal K, Eastwood SV, Michie S, Farmer AJ, Barnard ML, Peacock R, Wood B, Inniss JD, Murray E: Computer based diabetes interventions for adults with type 2 diabetes mellitus. Cochrane Database Syst Rev 2013, 3:CD008776

39. Watts S, Mackenzie A, Thomas C, Griskaitis A, Newton L, Williams A, Andrews G: CBT for depression: a pilot RCT comparing mobile phone vs. computer. BMC Psychiatry 2013, 13(49):1-9.

40. Ozer F, Moessner M, Bauer S: Economic Evaluation of e-Mental Health Applications. Global Knowledge Resources for Telemedicine \& eHealth; 2010. http://www.medetel.eu/index.php?rub=knowledge_resources\&page=2010.

41. Warmerdam L, Smit F, Van Straten A, Riper H, Cuijpers P: Cost-utility and cost-effectiveness of Internet-based treatment for adults with depressive symptoms: randomized trial. J Med Internet Res 2010, 12(5):e53p.1-e53p.11.

doi:10.1186/1472-6963-14-313

Cite this article as: Ye et al:: Effectiveness of internet-based interventions for children, youth, and young adults with anxiety and/or depression: a systematic review and meta-analysis. BMC Health Services Research 2014 14:313. 